\title{
OBE, Learning by Doing, and Blended Teaching in Principles of Economics for Foreign Students in China
}

\author{
Kun Luo ${ }^{1, *}$, Yangkun Wang ${ }^{1}$, Rendao $\mathrm{Ye}^{2}$ and $\mathrm{Ya} \mathrm{Lin}^{2}$ \\ ${ }^{1}$ Hangzhou Normal University, Hangzhou, PRC \\ ${ }^{2}$ Hangzhou Dianzi University, Hangzhou, PRC \\ *Corresponding author. Email: olivelk@163.com
}

\begin{abstract}
The course of Principles of Economics is compulsory for first year students who major in economics or management. To the end of providing quality higher education for foreign students in China, it still needs exploration as regards how to integrate new perspectives from the Chinese economic development and reforms into the existing knowledge system and make a breakthrough. Based on changes in practices and demand for professionals, the teaching content is to be restructured into a problem-oriented progressive system from fundamentals to explorations encouraging students' contribution. To better practice the outcomes-based education (OBE), we utilize the resources generated from cooperation with leading enterprises and integrate students' business practices into teaching, with a view of improving students' capabilities of learning by doing. Blended teaching modes and various online teaching activities are explored to inspire curiosity and enhance efficiency, which is of particular importance during the COVID19.
\end{abstract}

Keywords: Outcomes-based education, Learning by doing, Blended teaching, Online teaching.

\section{INTRODUCTION}

As a compulsory core course for first year students who major in economics or management, Principles of Economics is regarded as a first window through which foreign students perceive the quality of China's higher education. With great importance attached to the course, it needs exploration as regards how to integrate new perspectives from the Chinese economic development and reforms into the existing knowledge system and make a breakthrough in providing quality education. Furthermore, overseas higher education consists largely of online classes during the COVID19, subject to a variety of factors including time differences, information technology, and network infrastructure. It is of particular importance to improve efficiency by exploring blended teaching modes according to the characteristics and learning conditions of the course.

This paper is based on the teaching practices of the course for foreign students in our university. Section 2 introduces the course and several "pain spots" in teaching. Sections 3 and 4 explore the teaching content and modes respectively, on the grounds of outcomesbased education (OBE), learning by doing and blended teaching. We also reflect further on online teaching which is especially important at present.

\section{ABOUT THE COURSE}

The course is compulsory and core for first year foreign students who major in international business (in particular, cross-border E-commerce) in our university. It has been offered to 112 foreign students from 22 countries in total since 2019. In 2020, it was completely taught online due to the COVID19. Indeed, it has only been a short time since the teaching practices started. But owing to cooperation between the university and leading enterprises in the digital economy, explorations and reforms in teaching are endowed with resources.

Students' qualification can be ensured. Take students from Rwanda for example. As a resulting of cooperation between Alibaba Group of China and the Rwandan government within the framework of eWTP (electronic World Trade Platform), two Rwandan classes have been enrolled for the past two years in succession. Ranked top $10 \%$ in their college entrance examinations and outstanding in our recruitment process including tests and interviews, the students are strongly determined to engage in cross-border E-commerce practices and qualified with basic knowledge and learning abilities. In addition, most of them have received various scholarships and grants from both their 
government and the university, quite sufficient to avoid being preoccupied supporting themselves.

More importantly, thanks to cooperation between the university and enterprises, quite a number of students have started their business practices since their first year in China, such as live streaming and online store operation. Their business practices not only provide real and vivid first-hand teaching materials for the course, but also make it possible for students to learn better in practice and apply what they learn. Thus, the concept of learning by doing could be practiced.

There are also great challenges that can't be ignored, as regards how to integrate practical changes in the digital economy and cross-border E-commerce as well as new demand for business professionals, to break through the existing knowledge system, and to concentrate on cultivating students' abilities to observe and analyze realities. This is the matter of crucial importance in our teaching reforms. In addition, there exist some other pain spots in teaching. To start with, how to encourage first year students mostly indifferent to economics to get more engaged in exploring realities and acquire knowledge more efficiently? Secondly, how to cultivate their interests and capabilities of proactive learning? Last but not the least, how to better practice blended teaching with various forms and means of online activities during the COVID19? In view of these problems, we endeavour to explore reforms in teaching.

\section{RESTRUCTURING TEACHING CONTENT}

To the end of exploring economic realities, themes and topics covering new perspectives and insights in the development of the digital economy and cross-border Ecommerce practices are designed and introduced into the course. The teaching content is less modular than usual, and to be restructured into a problem-oriented progressive system from fundamentals to explorations encouraging students' contribution, enabling them to build up knowledge system via exploration of realities. Out of the total class hours of 48, the fundamentals such as conceptual cognition accounts for $34 \%$, while the extended explorations such as problem analysis, research project and case study accounts for $66 \%$.

Table 1 gives an example of the specific teaching content, activities and time arrangement in Section 1 Price Elasticity of Demand and Applications of Chapter 5 Elasticity and Applications. The class hours of this example are 2, namely 90 minutes, designed to fulfil four levels of teaching objectives progressively. As the fundamental conceptual cognition, objective 1 is designated with 15 minutes in class, accounting for $17 \%$ of the class hours of this example. Objectives 2 to 4 include case study, research project, and guidance on difficulties in students' research project, respectively. These extended teaching contents take up 72 minutes, accounting for $80 \%$ of the class hours.

Table 1. An example of teaching activities and time arrangement

\begin{tabular}{|c|c|c|}
\hline Teaching Phase & Teaching Activities & Time \\
\hline Bridge-in & $\begin{array}{l}\text { This example is just at the time of the Double Eleven Online Shopping Carnival in China, } \\
\text { cases and questions about which are uploaded as introductory materials to the DingTalk } \\
\text { class group so as to guide preview and self-learning. }\end{array}$ & $\begin{array}{c}5 \text { days } \\
\text { before class }\end{array}$ \\
\hline Pre-test & $\begin{array}{l}\text { Do a pre-test predesigned in the introductory materials by using the polling function of } \\
\text { the DingTalk class group }{ }^{a} \text {. Focus attention on wrong answers and misconceptions. }\end{array}$ & $\begin{array}{c}1 \text { day } \\
\text { before class }\end{array}$ \\
\hline $\begin{array}{l}\text { Objective 1: Conceptual } \\
\text { Cognition }\end{array}$ & $\begin{array}{l}\text { Briefly review before introducing this section. Guide students to consider predesigned } \\
\text { questions. Trigger discussion and establish students' cognition out of misconceptions. }\end{array}$ & 15 minutes \\
\hline Objective 2: Case Study & $\begin{array}{l}\text { Further the case study with four issues to be discussed in groups. Collaborate among } \\
\text { groups and integrate each group's viewpoints into a complete analytical framework. }\end{array}$ & 30 minutes \\
\hline $\begin{array}{l}\text { Objective 3: Research } \\
\text { Project \& Case Study based } \\
\text { on Students' Practices }{ }^{b}\end{array}$ & $\begin{array}{l}\text { Design case studies based on students' business practices during the Carnival. Guide } \\
\text { students to analyze specific practical issues. Further design research projects with specific } \\
\text { assignments and clear assessment criteria. }\end{array}$ & 22 minutes \\
\hline $\begin{array}{l}\text { Objective 4: Identification } \\
\text { \& Guidance on Difficulties } \\
\text { in Research Project }\end{array}$ & $\begin{array}{l}\text { Before this class, use the polling function of the DingTalk class group to identify the main } \\
\text { difficulties trapping students in their research. In class, give concrete and detailed } \\
\text { guidance on these difficulties under specific research backgrounds and problems. }\end{array}$ & 20 minutes \\
\hline $\begin{array}{l}\text { Post-test: Research } \\
\text { Findings, Presentation \& } \\
\text { Assessment }\end{array}$ & $\begin{array}{l}\text { Till next class ( } 7 \text { days later), follow up online on the difficulties, and give specific } \\
\text { guidance. Students carry out their research, and then present findings in the next class. } \\
\text { Assess students' performance in this section }{ }^{a} \text {. }\end{array}$ & next class \\
\hline Summary & Summarize especially the post-test. Notify the teaching content of the next class. & 3 minutes \\
\hline
\end{tabular}

Note: ${ }^{a}$ Results are to be counted in the overall course assessment, with Pre-test and Post-test (here in the form of Research Project) accounting for $10 \%$ and $20 \%$ respectively. ${ }^{b}$ This session consists of two parts with 1 week in between. The first part, as designed and conducted in this class, is to establish the theoretical framework, assign tasks and give guidance on difficulties, while the second part is arranged in the next class for presentation, discussion and assessment. 


\section{EXPLORING BLENDED TEACHING MODES}

\subsection{Blended Teaching Modes}

It contributes to the establishment of students' proactive learning behaviour and improvement of their learning abilities by applying proper teaching modes according to various objectives. Fundamental objectives are mostly accomplished via students' self-learning under guidance from the teacher, who identifies misconceptions online before class and leads discussion in class. For more extended objectives, teaching is accordingly more blended between class and online activities, more integrated with the teacher's interactive guiding and students' proactive learning. It mainly takes the forms of research project, case study, practical analysis, group collaboration and discussion, as well as competency training. The teacher needs to not only identify students' difficulties online in advance of class, but also follow up and give well-directed guidance in and outside class. Students no longer participate, but instead dominate their learning process and improve their capabilities of learning by doing.

The example given in Table 1 is just at the time of the most popular nationwide promotion carnival in China. Students' business practices of cross-border Ecommerce live streaming and online store operation during the Carnival could turn out to be highly demanding for professional competency. They are integrated into class activities such as case study and group discussion, and furthermore into research project outside class. Interesting practical issues regarding the pricing and marketing strategies drastically inspire students' curiosity and thirst for knowledge. While applying what they learn to practical issues, students are learning more efficiently by doing, thus significantly improving the quality of this blended teaching.

Blended teaching also calls for exploration of forms and means of online teaching, including bridge-in before class and follow-up after class, pre- and post-test, difficulties identification and guidance, as well as group cooperation. Apart from video websites and social platforms, the DingTalk.app also provides assistance with a wide range of functions including streaming, polling, testing, and presenting. To avoid monotonicity, however, other useful medium need to be developed and utilized. Take the Chinese university's massive open online courses as an example. As the most widely-used online teaching platform in China, its applicability for foreign students needs improving. Bilingual manuals and step-by-step demonstration are helpful for first year students. Still, more bilingual courses on such platforms, or moreover specialized platforms for foreign students, are expected to provide further solutions.
In view of the many differences among foreign and Chinese students in the way of thinking, information acquisition and social habits, we attempt to apply flexible and effective teaching methods. Usually before class, phenomena and cases close to their daily life or concerns are used to trigger discussion on the social media they're used to. We also make efforts to create learning atmosphere and good interaction by means of bidding simulation, overall awards and single prizes, group debate and collaboration, etc.

\subsection{Effects}

The above-mentioned exploration is achieving desired effects. Figure 1 shows students' feedbacks on whether "The teacher organizes class well and I'd love to participate". Out of the 88 respondents of several course evaluation surveys for the past two years, $82 \%$ graded "Very Good", and 12\% graded "Good". Up to $94 \%$ of the students believed the course was doing better than ordinary in stimulating their participation in class. Not a single student graded "Bad" or "Too Bad".

Figure 2 shows students' feedbacks on whether "Teaching methods are good and appropriate for us to gain better understanding". Up to $96 \%$ of the students are satisfied with the teaching methods, with $88 \%$ graded "Very good" and $8 \%$ graded "Good".

Throughout the course, especially with the advance of extended research projects and practical case studies, students begin to take on better performance in logics, argument and discussion, indicating improvement in learning abilities. Figure 3 shows feedbacks on whether "We have gained good understanding and improved learning abilities". 85\% graded this indicator as "Very Good", and $11 \%$ graded "Good".

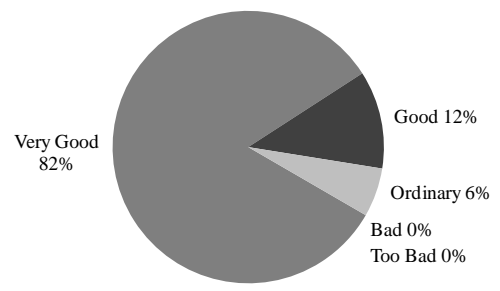

Figure 1 Feedbacks on whether "The teacher organizes class well and I'd love to participate"

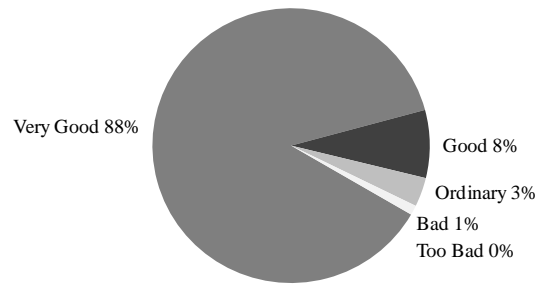

Figure 2 Feedbacks on "Teaching methods are good and appropriate" 
Table 2. Course evaluation before and during the COVID19

\begin{tabular}{|l|c|c|c|}
\hline \multirow{2}{*}{\multicolumn{1}{c}{ Indicator }} & \multicolumn{3}{c|}{ Mean (out of 100) } \\
\cline { 2 - 4 } & $\begin{array}{c}\text { Before (Offline } \\
\text { teaching mostly) }\end{array}$ & During (Online teaching only) \\
\cline { 2 - 4 } & 97.89 & 97.28 & 96.51 \\
\hline Overall evaluation of all 10 indicators & 98.55 & 96.87 & 94.09 \\
\hline The teacher sets clear requirements for us and we get along well. & 96.59 & 97.58 & 92.43 \\
\hline The teacher organizes class activities well and I'd love to participate. & 97.55 & 97.94 & 91.23 \\
\hline The teacher inspires us to learn and explore. & 98.05 & 98.26 & 97.83 \\
\hline We have gained good understanding and improved our learning abilities. & & \\
\hline
\end{tabular}

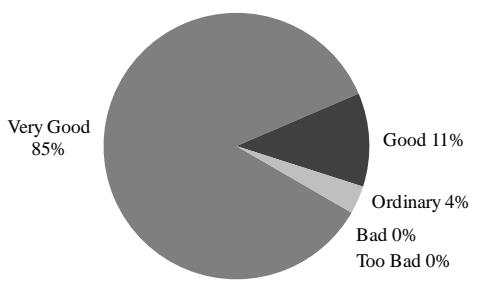

Figure 3 Students' feedbacks on whether "We have gained good understanding and improved learning abilities"

Source: anonymous course evaluation surveys in years 2019 and 2020 , conducted by the university.

\subsection{Further on online teaching}

The course was conducted completely online in the year 2020 due to the COVID19. With all efforts to ensure quality teaching, there still exist problems and inadequacies worthy of attention. Table 2 shows differences in the course evaluation results before and during the COVID19. For the course taught by the same teacher, the overall evaluation scores range from 96.51 to 97.28 in the case of online teaching only during the COVID19, moderately lower than before. Furthermore, evaluations of certain indicators are significantly lower, concerning teacher-student bonding, students' willingness to participate in class, motivation to learn, and improvement in learning abilities. It is evident that the teaching quality is severely restricted by the many defects of online teaching, such as relying on communication tools, conversation via devices only, and absence of learning atmosphere.

\section{CONCLUSION}

This paper explores reforms in the teaching of Principles of Economics on grounds of OBE, learning by doing and blended teaching. The teaching content is restructured into a problem-oriented progressive system from fundamentals to explorations encouraging students' contribution. Utilizing the resources generated from cooperation between the university and leading enterprises, we practice blended teaching modes and integrate students' business practices into teaching. Various forms and means of online teaching are also explored. Course evaluation results show that desired effects have been achieved, including stimulating participation, inspiring curiosity, and improving learning abilities. Still, the teaching quality is obviously restricted during the COVID19, and persistent exploration on online teaching deserves great attention.

\section{ACKNOWLEDGMENTS}

This research was supported by the Zhejiang Provincial First-class Undergraduate International Course Construction Project (Principles of Economics), and the Humanities and Social Science Projects of the Ministry of Education of China (19YJA910006).

\section{REFERENCES}

[1] C.P. Xu, Blended teaching modes of microeconomics based on OBE, in: Straits Science, 2020, pp. 76-79. DOI: 10.3969/j.issn.16738683.2020.09.019

[2] C.P. Zhang, J. Ramse, Teaching economics behind the global COVID-19 pandemic, in: International Review of Economics Education, 2021, 100206. DOI: https://doi.org/10.1016/j.iree.2020.100206

[3] G. Pan, V. Shankararaman, K. Koh, et al., Students' evaluation of teaching in the project-based learning programme: an instrument and a development process, in: The International Journal of Management Education, 2021, 100501. DOI: https://doi.org/10.1016/j.ijme.2021.100501

[4] H.M. Zhao, X.F. Sun, Y.Q. Yan, Practice and reflection of the online teaching of microeconomics course, in: Journal of Shanxi University of Finance and Economics, 2020, 42(S2), pp. 133-135.

[5] J. Li, C.L. Qin, Y.C. Zhu, Online teaching in universities during the Covid-19 epidemic: a study of the situation, effectiveness and countermeasures, in: Procedia Computer Science, 2021, pp. 566-573, DOI: https://doi.org/10.1016/j.procs.2021.04.100

[6] L.J. Jiang, S.Q. Jiao, N.W. Zhu, Quality course construction exploration and practice of Introduction to Economics for foreign students, in: Data of Culture and Education, 2020, (15), pp. 215217. DOI: $10.3969 /$ j.issn.1004-8359.2020.15.085 
[7] M.L. Xu, Mixed teaching design and practice of microeconomics-- take market equilibrium theory as an example, in: Pioneering with Science \& Technology Monthly, 2021, 34(01), pp. 141-143. DOI: $10.3969 /$ j.issn.1672-2272.2020.08.047
[8] S. Yao, D. Li, A. Yohannes, et al., Exploration for network distance teaching and resource sharing system for higher education in epidemic situation of COVID-19, in: Procedia Computer Science, 2021, $\mathrm{pp}$ 807-813.

https://doi.org/10.1016/j.procs.2021.03.002
DOI: 